\title{
Child Abuse in a Social Drama Film
}

\author{
By J. Emmett Winn \\ Spring 2005 Issue of KINEMA
}

\section{RADIO FLYER: THE THERAPEUTIC RHETORIC OF CHILD ABUSE IN A SOCIAL DRAMA FILM}

The United States continues to experience many social problems despite its relative wealth and power. The steady rise in child abuse is one of the most frightening. As Marc Miringoff and Marque-Luisa Miringoff point out, "Since 1976, child abuse has worsened by more than 300 percent" (75). The US Department of Health and Human Services reports that from 1986 to 1993 the abuse rates almost doubled. One might hope that much of this increase could be attributed to a rise in public awareness and, hence, an increase in the reporting of child abuse. Regrettably this is not the case. The escalations are "so dramatic the researchers judged them to be a 'true rise' in the severity of the problem" (Miringoff \& Miringoff 75).

The problem is fatally severe. The National Committee to Prevent Child Abuse reports that approximately three children are killed each day as a result of abuse. Moreover, the National US Advisory Commission on Child Abuse and Neglect estimates the number at 2,000 deaths per year (cited in US Dept. Of Health and Human Services). These alarming statistics point to a prevalent social problem. One significant question that arises is why, despite an effort at educating the population about child abuse, is the problem worsening? I argue that one important contribution to this crisis is a focus of American culture on individual change and therapy, a situation known as therapeutic ethos (Lears). In the US, child abuse is seen as an individual family problem, rather than a social problem, despite the fact that experts on domestic violence point to socioeconomic issues (such as poverty) and cultural factors (such as condoning physical force in child rearing) as significant contributors to child abuse (Freeman; Gill; Hopkins \& McGregor; Horsfall; Pagelow; Thompson). The result is that child abuse is understood as an individual problem by citizens of the United States and, therefore, social remedies may not be diligently pursued.

The current study utilizes therapeutic rhetoric to explore child abuse in the film Radio Flyer. Radio Flyer ameliorates the cultural distress concerning the widespread increase in child abuse by following a threestep program. First, the film reverts its abused children into their insulated traditional patriarchal family structure. Second, the movie constructs a rhetorical narrative that uses ambiguity and subjectivity to situate the audience to experience the events of the story from the perspective of the children and, accordingly, the film suggests a feeling of powerlessness in the face of child abuse. This powerless position causes emotional distress for the audience and, therefore, requires a solution to enable the viewers to find emotional relief. Finally, the film suggests a return to childhood imagination as a means of transcending the children's tragic conditions. In this way, Radio Flyer provides a rhetorical therapy for individuals concerned about child abuse. This essay extends the use of therapeutic rhetoric by explicating how popular film reinforces the supremacy of the traditional patriarchal family to the exclusion of social action in the United States' campaign to stop child abuse.

As Kim Golombisky points out, "some scholars suggest electronic media can function therapeutically during times of social tension by testing alternative resolutions" (66). Dana Cloud explains that "the therapeutic refers to a set of political and cultural discourses that have adopted psychotherapy's lexicon - the conservative language of healing, coping, adaptation, and restoration of a previously existing order" (xvi). David Payne explains that rhetorical analysis from a therapeutic approach "seeks to identify a psychology of interaction between a text and audience and explain why and how audience members may actively appropriate meaning from the text for therapeutic purposes" (28). In this way, viewers are able to draw experience from the film as they participate in the "enactment of particular values and behaviors" (Payne 28).

\section{Radio Flyer as an Important Social Drama Motion Picture}

Successful producer/director Richard Donner released Radio Flyer in 1992. Donner was at the time, and still is, famous for several blockbuster successes including the Lethal Weapon series (1987, 1989, 1992), The Goonies (1985), Superman (1978), and The Omen (1976). Donner was praised for his successful directing 
of Radio Flyer by film critic Jeff Strickler who lamented that "there aren't nearly enough [directors] who can make a film as intense, yet delicate, as Radio Flyer" (1E). The script, by David Mickey Evans, was heavily pursued by Hollywood production companies and started a "bidding war that ended with Evans getting paid $\$ 1.2$ million . . . for his first produced screenplay" which was a notably large sum (Turan F1). The screenplay was extolled by Rolling Stone film critic Pete Travers, "despite the [movie's] flaws, Evans' thoughtful script and the un-clichéd performances of Wood [Young Mike] and Mazzello [Bobby] exert a powerful grip. The film stays with you" (104). Moreover, the movie features the two-time Academy Award winner Tom Hanks, who enjoys continued popularity with audiences.

Yet the most significant rhetorical aspect of this text is its attempt to deal with the serious issue of child abuse. The film overtly offers itself as a socially conscious drama about child abuse by ending with a toll-free telephone number that viewers may call for information on child abuse (a singular event in feature films about child abuse). Furthermore, the film is often shown on national family programming cable channels, therefore, the movie continues to be seen by a broad audience and is widely known and recognized as an important film about child abuse. Moreover, since the late 1950s, television has been increasingly the primary medium for narratives that concern these types of social dramas, particularly the made-for-television-movie (Jarvik; Rapping). Therefore, the repeated inclusion of Radio Flyer on television suggests that the film is a significant social drama vehicle that reaches a large audience.

\section{Preserving the Traditional Family}

A critic applauded Radio Flyer as "a sensitive, sophisticated, deeply felt and deeply moving study of two youngsters with an indefatigable power to dream" (Strickler 1E). Radio Flyer is the story of two young brothers, Bobby (age 6) and Mike (age 10), growing up and coping with a drunken, abusive stepfather in the 1960s. The boys and their mother, Mary, relocate to California after their biological father abandons the family. In California, Mary meets and marries a man called The King. The King is aptly named as he assumes the role of the traditional family patriarch. Very early in the film the audience is shown the oppressive and abusive nature of the children's inescapably tragic environment. Mary is an overworked restaurant server who is absent from the house during most of her children's day. The King is verbally abusive to both boys and physically abusive to young Bobby when their mother is away, but the brothers are reluctant to tell her because they realize that she loves The King and their newly (re)formed family. The boys understand that their "new" family with The King as the head of the household is what their mother desires and believes is best for all.

The boys are torn between their own safety and their mom's happiness. Prior to their mother marrying The King and starting work, the brothers and their mother spend almost all of their time together and rely on each other for companionship and emotional support. The boys understand that Mary is depressed about their biological father leaving and they want to help her feel better. Mary's depression is highlighted in the film. For example, during the long drive to California, they happen upon a roadside attraction, Geronimo Bill's Wild West Adventure. There they meet the kindly old cowboy, Geronimo Bill, who allows the family to see his sideshow for free because he senses that they are experiencing economic hard-times. The family enters the show to find one lone buffalo. The brothers remark that the buffalo looks as lonely as their mom. As they leave, Geronimo Bill makes them promise to take care of their mother because he also senses her sadness. Once she meets The King, Mary is happy again and the boys sense that having The King in her life makes her feel better. Once she marries the traditional family structure is restored, and the threesome seeks to remake their family with The King as father.

Mike reports that after his biological father abandoned the family he knew his mom was depressed. When The King enters her life, she seems much happier, and the boys witness them enjoying each other's company. Likewise, Mike explains that his mother believes that The King is the answer to all her prayers. Therefore, Bobby does not want his mother to know about his beatings because he does not wish to force her to leave The King. The brothers' conscious desire and promise to care for their mother leaves Mike and Bobby in a situation in which they believe they cannot tell her about the abuse. They fear that telling her will force her to leave The King and once again break up the traditional family unit, resulting in her unhappiness. Jay Carr, film critic for The Boston Globe, points out that the audience is drawn into believing the children's reasoning, "you believe . . . in the thinking that leads [the boys] to decide not to tell their mother about their stepfather's abuses" (30). Because the boys cannot tell their mother about the abuse, they cope with 
their tragedy by creating a secret fantasy world where they can escape the harsh reality of their lives.

\section{Subjectivity and Ambiguity}

Ambiguity is the overriding structure of this movie. Its ambiguous nature is highlighted in the beginning where adult Mike warns his listeners that the truth of a story is in the mind of the teller and this ambiguity is maintained throughout the motion picture. The film is narrated from the perspective of the older brother, Mike, as he relates it to his two young sons in the present. Actor Tom Hanks, who is only seen briefly at the beginning and ending of the film but is heard in the voice-over narration of the entire movie, plays the adult Mike. Mike tells his sons the story as a life-lesson on the importance of keeping familial promises. He warns his sons that "promise" is one of the most important words a person can utter and that the commitment that accompanies a promise lasts a lifetime. He illustrates the truth of his claim with his story.

A subjective narrator is common in Hollywood cinema; however, in Radio Flyer, this subjectivity is emphasized by adult Mike's warning to his children. Mike begins the story by warning his boys that "history is all in the mind of the teller. Truth is all in the telling." At the conclusion he reminds the children that truth is in the telling and asks them if they understand. When they respond positively he replies, "Good, because that's how I remember." Mike's cautions before and after his story highlight the ambiguity of the narrative and its subjective nature. In addition, Hanks' voice-over narration invites the audience to identify with him and see the world from his perspective. In this way, the audience experiences the story from a child's perspective. This tempts the audience to view the abuse from the children's powerless perspective and invites the audience to accept the children's imaginative solution to their tragic situation.

Mike's story is about how he and Bobby coped with their abuse. Since the brothers do not feel that they can tell their mom about the abuse, they fashion a means of escape by building an improbable flying machine from their little red Radio Flyer wagon. In the climax, young Bobby attempts to fly the wagon by riding down a treacherous slope onto a ramp that propels the wagon high into the air. Mike tells his young sons that Bobby flew away to live a happy life free of abuse. The film visually reinforces this tale when, in a rare "objective" moment, the film shows young Mike receiving a postcard from Bobby who is happily flying around the world. The resolution is that Bobby flies away in his Radio Flyer wagon and lives his life as a pilot flying to various exotic locales. However, Bobby's flight is never actually shown and his life after the take off is not presented. The ambiguous ending further allows the audience to accept and revel in the miracle of Bobby's flight and the belief that he is safe and happy. As Carr explains, "[the children's] shared fantasy life is at once the truest and most touching thing about the film, indicating their resiliency and their way of fighting back against their entrapment in ugliness" (30).

Radio Flyer constructs a rhetorical narrative that uses ambiguity and a subjective point of view to situate the audience to experience the events of the story from the children's powerless perspective. In so doing, the film asks the audience to identify with the powerless and abused children and to accept imagination and fantasy as the solution to their situation. The audience is endowed with a powerless feeling as they must experience the narrative from the helpless perspective of the children. Since the film narratively and stylistically "locks" the viewers into young Mike's perspective, the audience is asked to view the events from Mike's powerless position. Young Mike has few and limited options other than his own actions; therefore, he struggles to solve the problem. Left with no other alternative, the audience must also struggle to find a suitable answer from this perspective. The answer is for the children to "lose themselves in a dream world that is filled with fun and adventure" (Strickler 1E). The solution comes through embracing childhood imagination.

\section{The Power of Imagination}

Childhood fantasy is important to containing the tragedy of Radio Flyer by urging the viewers to embrace the power of imagination. Focusing on the children's imaginative fantasy beckons the audience into the kids' fascinating private world. Radio Flyer must be able to perform this move because of the film's need for the audience to embrace its miraculous resolution. The "Fisher Legend" is one narrative element that functions in helping the audience to understand the children's world. Adult Mike begins his story with the telling of a legend that he and Bobby heard as children. The story is about Fisher, the boy who flew. The legend states that Fisher rode his bicycle down a steep hill and up a ramp that launched him high into the air. Fisher lands hard but lives, and he is lauded by his friends as a hero because he has "flown." The Fisher Legend flourishes among the children of the area, and ten years later when young Bobby and Mike arrive in the 
town, they soon learn of it and are in awe of Fisher's fearless feat. Importantly, Fisher's heroism becomes an impetus for Bobby's quest to fly.

As well, Mike explains the "seven magical abilities" of children. He posits seven childhood secrets are lost when a child reaches the age of 12-13 years and discovers "the opposite sex." Mike lists the seven magical abilities: Animals can talk, a child's favourite blanket is a force-field, nothing is too heavy to lift while wearing a cape, your finger can fire real bullets, you can jump safely from great heights with the aid of an umbrella, monsters exist and can be fought, and that children have the ability to fly. The discussions of these magical abilities add to the viewers' restored sense of mystery and enchantment in everyday life and serve to help contain the tragedy of the abuse.

The imaginative quality of this film is its charm as the viewer is continually pulled into the private realm of childhood imagination. Film critic Catherine Dunphy explains, "Radio Flyer explores [the children's] world . . . gives it the intensity all kids have for their private terrain, infuses it with their magic, their faith. You feel Bobby's whole soul yearning to fly. You believe enough to wish it could have been your childhood" (D10). By concentrating on the brothers' fantasy, the movie invites the audience into the boys' charming imaginative world which is a welcome respite from the harsh and tragic reality of their abuse. The therapy involves recapturing youthful innocence by embracing the magic of childhood fantasy, thus transcending the corporeality of abuse.

\section{The Miraculous Resolution}

Each of the two brothers have elements or parts of a quest that occur in Radio Flyer. Bobby's is to fly. Mike's quest comes to him in a dream and involves helping Bobby to realize his dream to fly. These are goals with which the audience can identify and encourages the viewers that the boys have plans that will, hopefully, save them from their abusive stepfather.

Young Mike's quest comes in the form of a charge. After a harsh beating that Bobby receives at the hands of The King, Mike is visited by a dream mentor. In the dream, young Mike is awakened by noise in his back yard. He arises and goes to the window and looks out with his flashlight. The children's shack-like fort is shaking and emitting rumbling sounds. In slow-motion footage the fort begins to swell as something inside it grows larger until it shatters the structure revealing the buffalo from Geronimo Bill's. The buffalo/mentor tells Mike (in Geronimo Bill's voice) that Bobby's situation is worsening but that Mike can help. The buffalo explains that Bobby can find the answer to his problems "inside himself" and that Mike can aid him in understanding. Mike explains that "the dream had given me strength and a sudden sense of purpose." That purpose is his charge to help Bobby find the answer "locked inside." Therefore, the boys need Bobby's imagination to sort out a plan of escape and Mike's pragmatism to build the Radio Flyer. The resolution of both goals and the climax of the film results when Bobby flies the Radio Flyer to safety, and The King is concurrently arrested.

This resolution offers a type of tragedy containment, the hope that the boys can escape the horror of their lives. Although acceptance of the flight works to contain the tragedy of the child dying and provides for a more satisfying resolution, the act is entirely improbable. Perhaps the most obvious contradiction to the miraculous ending is Samson, the brothers' turtle. Samson is present with Adult Mike and his sons at the end of the film. This fact calls the veracity of Bobby's flight into question. In Mike's story, Samson accompanies Bobby on the trip in the Radio Flyer. The motion picture makes it a point to highlight Samson's presence on the Radio Flyer by both showing him on board and by having young Mike address him, "Goodbye Samson, be a good turtle and have a good ride." Whereas, the presence of the turtle with Mike's children supports the idea that Bobby did not actually fly away.

Bobby is a sensitive person unable to exist in the harsh environment that crushes him mentally and physically. The tragic reading of the conclusion demonstrates the inevitable - that Bobby's frail and troubled life must end in the disastrous, but not depicted, crash of the Radio Flyer. In that sense, the ending affirms the lesson that the imaginative life is doomed to fail in the harsh reality of living. Mike's story that Bobby flies away, suggests some transcendence through the miracle of imagination and some containment of the tragedy; however, this is not a joyous resolution as it simultaneously signals the end of the imaginative self. In this sense, the ending is tragic regardless of whether Bobby flies away or dies, because Bobby is sacrificed so that Mike can go on to (re)establish a private family with himself at the head. The results of the abuse are 
the same: Bobby is removed, he is sacrificed, and the harsh realities of child abuse are left without the film having to offer an overt condemnation or even serious social criticism. Adult Mike's story is an overt parable to his sons on the importance of keeping promises and implicitly a lesson in the significance of the family as a sacred and private group.

Mike's quest to help Bobby fly is admirable, but it is the key to his failure. His responsibility to both his mother and little brother lies in his ability to choose the mature decision to break his promise and tell someone who can help. Yet the film only chooses imagination as the brothers' way out. For example, when the small town's sheriff senses something is wrong he tells the boys that if they need him he will help. The audience can see this as a possible resolution to Mike's predicament. However, the incident coincides with the arrival of a mail-order "anti-monster" magic-potion that the brothers ordered from an advertisement in a comic book. Mike and Bobby see this potion as the answer to their problems and so the real help offered by the law-enforcement official is not accepted. Mike chooses fantasy over the sheriff's offer because it allows him to keep his promise to Bobby and is in keeping with the motion picture's focus on imagination.

Mature audience members, however, realize that the magic-potion is a typical comic book advertiser's hoax. The viewers are again frustrated by the narrative being centred in a child's world where this magical possibility is favoured. Mike's responsibility to his family requires that he break the promise and seek help from outside the family. In fact, to be successful Mike must choose to break his promise.

\section{Focus on the Family as Therapeutic}

Radio Flyer communicates a prescriptive rhetoric of "family." That focus begins with adult Mike teaching his sons about the importance of familial promises and is carried throughout the film as Mike and Bobby suffer from abuse but refuse to tell their mother for fear of breaking up the newly reformed patriarchal family. Mike desperately wants to stop The King from beating Bobby. Mike remarks to his own children that he never told his Mom about the beatings and "that bothered me a lot." Yet, Mike grants Bobby's wish not to tell their mother. This promise combined with the pledge to Geronimo Bill to take care of his mother gives Mike a tremendous sense of responsibility. He feels responsible for his mother's happiness and brother's safety. This responsibility creates a paradox for Mike. How can he reconcile these responsibilities? If he tells his mom, she will lose The King, the traditional family structure will be broken again, and Mary will be unhappy. If he does not tell, then he cannot stop the beatings. Therefore, he must live with the dilemma and pain of the situation. The film's overriding theme of responsibility to maintaining the traditional patriarchal family structure is intertwined with the stated importance of keeping familial promises.

Mike knows that he must keep his promise not to tell, but he is not sure how to maintain his promise to Bobby and survive at the same time. In his dream, the buffalo tells him to help Bobby find the answer that is "within him," and Mike takes this quest as his own. Payne explains that past rhetorical analyses of films:

Formulate the therapeutic rationale of a text as the structure or form whereby experience of the text arouses or exacerbates some psychological discomfort that the story's resolution helps to ameliorate or assuage. Persuasion or reorientation to some scheme of values is seen as the result of this psychological involvement. (28-29)

Ultimately, Mike resolves his dilemma by helping Bobby fly. The film's reliance on Mike's perspective leaves the audience with imagination as the boys' only hope. Dana Cloud explains "the discourse of therapy serves a broader, cultural function for mass audiences: to offer psychological ministration for the ills of society" (ixv). In Radio Flyer, the film overtly turns the viewer's gaze from the harsh physical realities of child abuse to the magical possibilities of childhood imagination. In so doing, the problem of child abuse is transcended via a charming tale of childhood fantasy.

Radio Flyer's therapeutic rhetoric is one of accepting the primacy of the traditional family and in keeping familial promises - the purpose of the life-lesson. The film suggests that a focus on the family rather than individual family members is what is most important. Payne explains that, "Participating in the rhetoric of a text may allow individuals to reorient toward and resolve tensions. . . . Texts . . . can speak to typical audience problems and situations, enjoining the viewer in a prescriptive rhetoric that shows how such problems ought . . . [to] be resolved (28-29). Radio Flyer provokes psychological uneasiness in the viewer by creating a feeling of powerlessness. The audience member experiences the terror of the abuse from the 
children's perspective. By keeping the focus on the family, the movie suggests that this is a problem for this family to solve.

By focusing on the private, the imaginative, and the traditional patriarchal family, the movie shuns social or cultural aspects of the problem of child abuse. Child abuse statistics make it clear that this is a significant social problem (Miringoff \& Miringoff). Domestic violence experts argue that economic problems such as poverty and cultural practices such as the use of physical force in raising children are important contributors to child abuse (Freeman; Gill; Hopkins \& McGregor; Horsfall; Pagelow; Thompson). Although the problem cannot be solved by completely ignoring the family unit, looking at child abuse as a community, social, and cultural problem offers troubled individuals and private families badly needed support.

Social and cultural conditions contribute to child abuse. For example, sexist labour conditions force many women to work long hours at low paying jobs in order to survive economically, thus forcing them often to be reliant upon an abusive spouse for support. Further, the "spare the rod and spoil the child" macho patriarchy encourages the use of violence to discipline children. This suggests that families need external help to break the cycle of abuse. Yet, this film implicitly argues, instead, that the abuse must be resolved within the family, and the movie rejects external intervention as a suitable resolution.

The conservative focus on the family ignores the need for social action. The result is that the social problem of child abuse is worsening, and as long as US society maintains a focus on the therapeutic ethos, then the larger social and cultural issues that contribute to this problem can never be fully addressed and there will be little hope for improving what has become a crisis in America.

Finally, women and children in abusive families have little chance for individual action. Statistics show that abusive husbands are much more likely to kill their spouses if they leave the abusive home and the economic realities of life are stacked against single mothers. With their lives in danger and their children's economic well-being at stake it is very difficult for women to escape. Instead of a focus on the therapeutic of the individual, what is needed is social change via public action to improve the rights of abused women and children in the United States.

\section{References}

\section{Works Cited}

Carr, Jay. "Radio Flyer Could Have Been Great." Boston Globe 21 Feb. 1992: 30.

U.S. Department of Health and Human Services. Child Maltreatment 1996: Reports from the States and the National Child Abuse and Neglect Data System. Washington, D.C.: U.S. Department of Health and Human Services, Children's Bureau, 1998.

Cloud, Dana L. Control and Consolation in American Culture and Politics: Rhetorics of Therapy. Thousand Oaks, CA: Sage, 1998.

Dunphy, Catherine. "Cute Fantasy Wraps Child-Abuse Horrors in Warm, Fuzzy Tale." Toronto Star 21 Feb. 1992: D10.

Freeman, Michael, ed. Overcoming Child Abuse: A Window on a World problem. London: Dartmouth, 2000 .

Gill, David. G. Violence Against Children. Cambridge, MA: Harvard UP, 1973.

Golombisky, Kim. "Mothers, Daughters, and Female IdentityTherapy in How to Make an American Quilt." Western Journal of Communication 65 (2001): 65-88.

Hopkins, Andrew \& Heather McGregor. Working for Change: The Movement Against Domestic Violence. Sydney: Allen \& Unwin, 1991.

Horsfall, Jan. The Presence of the Past: Male Violence in the Family. Sydney: Allen \& Unwin, 1991.

Jarvik, Laurence. "'It's Only a Movie:' The Television Docu-drama and Social Issue Movie as the American Market Place of Ideas." Studies in Popular Culture XI (1998): 80-96. 
Lears, Jackson. "From Salvation to Self-realization: Advertising and the Therapeutic Roots of the Consumer Culture, 1880-1930." The Culture of Consumption. Eds. Richard Wightman Fox \& T. J. Jackson Lears. New York: Pantheon Books, 1983. 1-38.

Miringoff, Marc L. \& Marque-Luisa Miringoff. The Social Health of the Nation: How America is Really Doing. New York: Oxford UP, 1999.

Pagelow, Mildred. D. Family Violence. New York: Praeger, 1984.

Payne, David. The Wizard of Oz: Therapeutic Rhetoric in a Contemporary Ritual. Quarterly Journal of Speech 75 (1989): 25-39.

Rapping, Elayne. The Movie of the Week: Private Stories, Public Events. Minneapolis: University of Minnesota Press, 1992.

Strickler, Jeff. "Intense 'Radio Flyer' Isn’t Kid Stuff." Star Tribune 21 Feb. 1992: 1E.

Thompson, Ross. A. Preventing Child Abuse Maltreatment Through Social Support: A Critical Analysis. Thousand Oaks, CA: Sage, 1995.

Travers, Pete "Radio Flyer." Rolling Stone 19 March 1992: 104.

Turan, Kenneth. "Radio Flyer: A Flashback to Childhood Daze." Los Angeles Times 21 Feb. 1992: F1, F12.

\section{Author Information}

J. Emmett WINN is Professor in the School of Communication and Journalism at Auburn University (Alabama). He is the author of Documenting Racism: African Americans in US Department of Agriculture Documentaries, 1921-42, The American Dream and Contemporary Hollywood Cinema, and co-editor of Transmitting the Past: Historical and Cultural Perspectives on Broadcasting. His scholarly articles have appeared in Critical Studies of Media Communication, The Journal of Broadcasting and Electronic Media, Film and History, among others. 